\title{
POLÍTICAS EDUCACIONAIS E TRABALHO DOCENTE NA ESCOLA PÚBLICA: QUESTÕES CANDENTES
}

\section{EDUCATIONAL POLICIES AND PUBLICH SCHOOL TEACHER WOK: ISSUES ON THE SCENE}

\author{
Susana Scherer \\ Universidade Federal de Pelotas
}

\begin{abstract}
Resumo
Este estudo objetiva analisar as políticas educacionais e aferir algumas de suas implicações sobre o trabalho docente na escola pública brasileira. Abrange um olhar multidimensional sobre a docência, no âmbito das questões globais (do Estado e das políticas educacional), reconhecendo as inferências de cunho neoliberal, sustentadas na ideia de Nova Gestão Pública (NGP), e nos mecanismos de gerencialismo e performatividade. Os resultados da pesquisa reconhecem a presença da NGP e do gerencialismo na educação nacional, principalmente, através de avaliações externas e em larga escala com estudantes e docentes como ferramentas para medir a qualidade educacional, metas e desempenhos como princípios via Índice de Desenvolvimento da Educação Básica (IDEB), e ações no campo da formação e seleção de professores assim como da avaliação daqueles professores já atuantes nas escolas, repercutindo em mudanças sensíveis com a construção de um perfil de professor orientado pela performatividade.
\end{abstract}

Palavras-chave: Políticas públicas educacionais; trabalho docente e escola; performatividade e gerencialismo.

\begin{abstract}
This study analyzes the educational policies and assess some of their implications in Brazilian public school teachers work. The discussion covers a multidimensional view of teaching, in the context of global issues (State and educational policies), recognizing the inferences of neoliberal, and the ideas of New Public Management (NPM), and the mechanisms of managerialism and performativity. The research results identify the NPM and managerialism presence in national education, mainly through external and large-scale evaluations to students and teachers as quality indicators, the Basic Education Development Index and it goals and performance as principles, as well as teacher training and selections also mechanism to evaluate and orient that already teachers in school, reflecting in the construction of a kind of teacher oriented by performativity.
\end{abstract}

Keywords: Public educational policies; teaching work and school; performativity and managerialism. 


\section{INTRODUÇÃO}

Este estudo objetiva analisar as políticas educacionais e aferir algumas de suas implicações sobre a docência na escola pública brasileira. Tem-se como pretensão, tal qual o apontado por Oliveira (2004), projetar um olhar multidimensional sobre o trabalho docente.

Nessa perspectiva, o trabalho docente é compreendido como uma forma de trabalho social particular, que é um campo político, sobretudo, no bojo de uma sociedade com projetos em disputa (KUENZER, 2011; OLIVEIRA, 2004). Assim, são contemplados os impactos do processo de reconfiguração capitalista econômicoprodutiva, iniciada nos anos 1990 e em plena vigência, produzindo, para além de transformações na esfera produtiva e econômica, uma nova conformação social, por meio de uma proposta de redefinição do Estado e no tocante de seu papel enquanto ente de materialização das políticas públicas, e nessa linha também com reflexos na educação, na escola e na profissão docente.

No cerne das intenções deste estudo se analisa o modelo de Nova Gestão Pública (NGP), assumido no quadro do neoliberalismo, segundo um tipo de Estado Gerencial que se expressa, entre outros itens, pela performatividade, e concretiza mecanismos de responsabilização (accountability), padrões (standars) e sistemas avaliativos (MAROY; VOISIN, 2013).

$\mathrm{Na}$ educação pública brasileira se destaca o papel assumido pelo Instituto Nacional de Estudos e Pesquisas Educacionais Anísio Teixeira (INEP), órgão vinculado ao Ministério da Educação (MEC), criado para gerir as avaliações nacionais e aferir a qualidade educacional.

Assim, a escolha por estudar as ações realizadas pelo INEP foi intencional. Analisam-se documentos legais e oficiais do instituto, notícias e outras informações, veiculadas em seu site oficial ou em outros espaços da mídia, compreendendo que esses materiais dizem muito, ecoam objetivos, metodologias e, finalidades que produzem concepções educacionais e docentes, mas que, algumas vezes, não são claros, requerendo um trabalho minucioso de análise e mapeamento dos interesses que lhes subjazem (SHIROMA; CAMPOS; GARCIA, 2005). 
Depois, cotejam-se os resultados dos documentos analisados com as teorizações sobre o tema, buscando refletir sobre as implicações destas políticas educacionais na docência.

O horizonte assumido nessa pesquisa se coaduna às perspectivas críticas da sociologia de educação, da qual se filiam Ball (2009) e Mainardes (2006), dando ênfase aos processos macrossociais e micropolíticos, com a finalidade de analisar a completude envolvendo o espaço da política educacional para além do que acontece e é visível na realidade escolar, refletindo-se mais profundamente a respeito de questões sobre o projeto de educação e sociedade em curso.

Para Ball (2009), uma política é quase como o processo de atuação em uma peça teatral, na qual se têm as palavras do texto que precisam ser transformadas em ação, e que na particularidade educacional tem como protagonistas a figura dos professores.

No entanto, como diz Mainardes (2006), embebido dos pressupostos de Bernstein, as políticas são discursos e moldam ações e concepções. Logo, é preciso identificar tudo o que envolve o processo escolar, e que vai muito além do que simplesmente parecem ser ou do que se vê em sua superfície, levantando-se em conta as relações históricas, de poder e os interesses envolvendo o fenômeno educacional, e que não são de forma alguma um dado harmônico e neutro, mas um produto e produtor de orientações e que aqui, neste foco, manifestam-se no cotidiano de sala de aula através do trabalho dos professores, como um dos elementos principais.

Assumindo-se tais desafios se usa como amparo a abordagem do ciclo de políticas, apresentada em estudos de Ball (2009) como um modelo de orientação para a pesquisa em política educacional. Ele é sistematizado em três grandes contextos: (1) o contexto de influência e estratégia política; (2) no contexto da produção do texto; e (3) o contexto da prática escolar e de seus efeitos. Tal proposta tem em vista conceber as relações entre os três contextos de modo interativo e alinear. Contudo, pode-se dizer que a numeração de 1 a 3 tem em vista apresentar um modo de orientar a pesquisa, do global para o local, ou do contexto até a realidade. Assim, parte do contexto em que as políticas nascem no campo da luta das ideias e disputas pelos sentidos da educação, passando pela sua culminância nos textos e materiais políticos consolidados pelo Estado, até a sua materialidade na prática escolar. Assim, cabe reconhecer que cada um destes espaços 
possui especificidades, mas podem existir vinculações e os contextos se intercalarem.

A partir desses horizontes, para sustentar o estudo, a reflexão se encontra organizada em três partes. Na primeira, situa-se o contexto de disputas e influências sobre a docência, no âmbito de elucidar as questões macrossociais, políticas e estatais, especialmente, as diretivas propagadas pelo projeto capitalista neoliberal na orientação do Estado e das políticas de educação, sobretudo, àquelas voltadas aos docentes.

Depois é delineada a forma de Estado Gerencial, no cerne da perspectiva de NGP que é disseminada pelo projeto econômico capitalista global. Aludem-se seus princípios e suas implicações sobre o setor público e as formas políticas desenvolvidas. Feito isso, é explicitada a lógica gerencialista assumida na educação brasileira e evocando um tipo de Estado Avaliador, baseando-se, para tal, na análise de documentos legais e oficiais, as iniciativas políticas deliberadas, e o cotejamento desses dados com a literatura sobre o tema.

Ao final, buscam-se tecer alguns dos principais desdobramentos decorrentes do modelo de políticas avaliativas externas e em larga escala levadas a cabo no Brasil, em nível de exprimir reflexos nos docentes e na escola pública.

\section{Os movimentos permeando o professor: Conjecturas sobre as políticas educacionais}

Parte-se da prerrogativa de que o trabalho docente não está alheio ao cenário macrossocial. Assim, constata-se um quadro importante de reflexos no contexto particular do capitalismo que, perpassado por uma crise, assume como principais estratégias de superação: o neoliberalismo, a globalização e a reestruturação produtiva (HARVEY, 2013; MÈSZÁROS, 2013), as quais, "redefinem o papel do Estado, principalmente para com as políticas sociais [...] entre elas a política educacional" (PERONI, 2010, p. 1), inclusive, escolar e docente.

Globalização exprime o processo de unificação dos mercados mundiais pela expansão das finanças globais, a fim de possibilitar lucros com investimentos especulativos fluidos e desregulados, mediados por grandes grupos econômicos multilaterais, tais a Organização para Cooperação e Desenvolvimento Econômico

@rquivo Brasileiro de Educação, Belo Horizonte, v. 9, n. 18, 2021 
(OCDE) e o Banco Mundial (BM).

Conforme Antunes (1999), o programa global infere em transformação na forma de acumulação produtiva fordista, repercutindo em mudanças na completude do mundo do trabalho e dos trabalhadores, e, em consequência, na vida social, política e cultural como um todo.

No mundo do trabalho e dos trabalhadores o modelo produtivo industrial padronizado, do executor brutalizado e operador rígido de funções programadas, definidas e controladas é substituído pelo trabalhador terceirizado, precarizado, subcontratado, flexível e em tempo parcial, e com o esvaziamento de direitos laborais em sua forma universal. A partir disso, é suscitado o envolvimento total do operário na produção, com a valorização de aspectos como empreendedorismo, cooperativismo, voluntariado etc.; assim como do espírito de trabalho em equipe com vista a maior produtividade e na qual cada trabalhador controla a si mesmo e seus pares para garantir a qualidade; destarte a um combate cerrado ao sindicalismo e a propagação de discursos individualistas e meritocráticos. O objetivo é a captura subjetiva do funcionário para que lhe não reste nada mais do que senão pensar e fazer pelo e para o capital (ANTUNES, 2001).

No campo político os preceitos neoliberais embasam a passagem do Estado de bem-estar, prevalecente no Pós-Guerra até a crise de 1970 se fortalecer. Sua proposta prevê processos de privatização, com o enxugamento do papel estatal na provisão pública via direitos sociais. Tal paradigma ganhou terreno no governo de Margaret Thatcher (Gestão Partido Conservador, 1979-1990), no Reino Unido para superar o modelo de bem-estar keynesiano, que concedia benefícios sociais e trabalhistas (ANDERSON, 1995).

O neoliberalismo coloca a culpa da crise nos amplos gastos, sobretudo, no atendimento de demandas populares através de políticas sociais, conforme as que eram propiciadas pelo Estado keynesiano, entendendo as políticas sociais como forma de distribuição de renda e de saque à propriedade privada e as possibilidades de progresso individual, além da democracia popular como prejudicial para o caminho do livre mercado. Propõe, então, um tipo de Estado mínimo na execução e coordenação da vida social, quanto a direitos, bens sociais e com incisivas penas à democracia em sua forma 
pública, assumindo-se como novo parâmetro, daí em diante, um modelo de gestão pública consonante à qualidade do mercado.

Essas questões são importantes, pois na especificidade do setor público, os professores, são partes da materialização do Estado e das formas que ele assume em suas ações. Quer seja, entende-se que "a política educacional não é, simplesmente, determinada pelas mudanças macrossociais e econômicas, mas é parte constitutiva" (PERONI, 2013, p. 3). Logo, as mudanças na educação são partes do movimento social, econômico e político mais amplo, o qual, sobretudo, no período particular do programa neoliberal incita redimensionamentos no papel do Estado para com o tratamento das políticas sociais, o que reflete sensivelmente nas políticas educacionais, e, consequentemente, nos professores escolares.

De acordo com Ball (2001), no campo da educação a globalização imprime um novo paradigma de governo educacional o qual repercute no desaparecimento gradual das políticas específicas sociais específicas de cada país, dando lugar à construção de uma zona global comum situada e articulada em nome de um novo pacto entre Estado e capital. E para remodelar a educação e o setor público a esse novo modelo se tem a instalação de um conjunto de tecnologias políticas para disseminar novos valores, relações e subjetividades cotidianas (BALL, 2001).

Conforme Hood (1995), para disseminar os pressupostos administrativos para a revitalização do metabolismo capital pós-1970 são em prol de uma NGP, baseada em metas, padrões de desempenho, foco no resultado e em eficácia, e na responsabilização centrada no self, em liderança, auditorias etc. Para Clarke e Newman (2012), a NGP injeta um tipo de Estado Gerencial, com o ímpeto, essencialmente, de metamorfosear o sentido da qualidade do setor público para assemelhá-lo ao mercado.

Conforme Ball (2001, p. 104), a introdução da forma empresarial na provisão pública institui uma "nova relação do Estado com o setor público", o que faz emergir um ambiente moral de reconstituição do preceito de ética, que se orienta para servir as necessidades do/a cliente e do julgamento comercial. Consolida-se, nesse quadro, uma comunidade cultural corporativa, na qual as relações de compromisso individual e ação organizativa cedem espaço para relações entre gestão e performatividade, e que se pautam pelo aumento da individualização ao passo da destruição da solidariedade e de 
identidades profissionais comuns e baseadas em filiação sindical. Legitimam-se, por fim, processos de mercantilização do setor público e de seus funcionários, uma vez que: "profissionalidade é substituída por responsabilização, coleguismo por competição e comparação interpessoal de performances” (BALL, 2006, p. 15).

A gestão gerencialista funciona como instrumento de administração para mudar a estrutura e a cultura dos serviços públicos introduzindo novas orientações e criando relações de poder no cotidiano escolar e de forma mais ampla nas políticas sociais (BALL, 2005). Esta forma de gestão se impõe utilizando comparações e julgamentos ao invés de intervenções e direção, segundo Ball (2014), via auditorias, inspeções, avaliações e autorrevisões a fim de garantir a qualidade, sistemas de avaliações e de indicadores para produzir um indivíduo autogerenciado e autônomos. Isso permite moldar desempenhos e, consequentemente, sujeitos e relações sociais que acabam por tornar "o indivíduo uma empresa, [...] uma unidade produtiva de automaximização que opera em um mercado de desempenhos" (BALL, 2014, p. 67).

Tal modelo de gestão empresarial permite ampliar o leque de controle do comportamento dos profissionais públicos se combinando com a performatividade. Performatividade refere-se aos "terrores (soft e hard) de desempenho e eficiência" - o que significa: "seja operacional (ou seja, comensurável) ou desapareça”, diz Ball (2005, p. 544). Compreende, em síntese, o processo de mercantilização profissional, imprimindo sentimentos de responsabilização nos próprios sujeitos pelo sucesso da educação, em contrapartida da desresponsabilização do Estado.

Em suas contribuições, Ball (2014) diz que a performatividade tem uma ação tanto individualizante quanto totalizante, produzindo docilidade ativa e produtividade sem profundidade. Pois, quando os desempenhos se tornam o eixo de orientação da escola se produz um arcabouço de incertezas, incompletudes que trabalham poderosamente por dentro das cabeças das pessoas e atingem a totalidade do ser humano, fazendo os sujeitos querer trabalharem duro, cada vez mais rápido e de um modo sempre melhor e no qual buscam impulsionar sua produtividade, como parte de autovalorização e da sua equipe. Enfim, é oferecida uma incansável concorrência em se atingir a excelência, sendo melhor do que se era e até melhor do que os outros em seus próprios termos que retira de cena debates mais amplos sobre compromissos sociais e 
educacionais da escola.

Assim, reconhece-se a pertinência de analisar a presença e reflexos destes movimentos e seus impactos na docência, uma vez a performatividade se apresenta como um mecanismo político central na modificação dos sujeitos e relações, caracterizando-se por critérios de responsabilização, competividade, individualismo, meritocracia, entre outros princípios que se afastam de um programa de educação pública manifestado por justiça, igualdade e democracia.

\section{As políticas educacionais e suas implicações no trabalho docente no Brasil.}

No Brasil, Peroni (2013) aclara as orientações gerenciais assumidas para o Estado nacional a partir do Plano Diretor da Reforma do Estado (PDRAE), efetivado no primeiro mandato de Fernando Henrique Cardoso (FHC, Gestão PSDB, 1995-2002).

Conforme Adrião e Peroni (2009), o PDRAE apresentou influências neoliberalistas ao alocar a crise no Estado e sugerir como resposta adotar o modelo gerencial, de forma a "[...] reformá-lo, por meio da adoção de mecanismos de gestão vigentes no campo empresarial” (p. 109). Em seu diagnóstico o plano colocou os funcionários públicos e o investimento em políticas sociais como os culpados pela crise, prevendo para superar tal cenário a ênfase do Estado na lógica mercantil e a inclinação do eixo político-social em critérios de maior eficiência e eficácia da máquina pública via processos de descentralização das responsabilidades estatais ao passo da promulgação de maior autonomia escolar e docente (PERONI, 2013).

$\mathrm{Na}$ sua aplicação no setor educacional e escolar, o Estado gerencial se embasa em modelos de Estado avaliador, identificados por Maroy e Voisin (2013), por aqueles que,

[...] implantam sistemas de indicadores nacionais que lhes permitem "dirigir" o sistema, "controlar" melhor o processo e o funcionamento das escolas ou dos órgãos de gestão escolar de nível intermediário. Além disso, os procedimentos para avaliar os resultados dos estabelecimentos e, indiretamente, o trabalho dos professores são elaborados acompanhados de mecanismos mais ou menos instantâneo de prestação de contas. Estes dispositivos de accountability são supostamente para garantir a gestão de todo o sistema educativo, orientar para certas prioridades e controlar a qualidade. [...] A meta declarada é a de melhorar a eficácia do ensino, reduzir as desigualdades e diferenças de desempenho entre grupos de alunos (a equidade), enfim controlar ou então reduzir os custos, ou seja, melhorar a eficiência. A escola

@rquivo Brasileiro de Educação, Belo Horizonte, v. 9, n. 18, 2021 
fica, dessa forma, cada vez mais sujeita a obrigação de resultados e de desempenho (p. 882).

No caso brasileiro se observa com destaque o papel assumido pelo INEP, autarquia federal vinculada ao MEC, "cuja missão é promover estudos, pesquisas e avaliações sobre o Sistema Educacional Brasileiro com o objetivo de subsidiar a formulação e implantação de políticas públicas para a área educacional a partir de parâmetros de qualidade e equidade, bem como a produção de informações claras e confiáveis" (INEP, 2020). Especificamente, no que refere à escola, o instituto desenvolve seis ações nucleares, contornando de um índice escolar a avaliações em larga escala, para estudantes de todas as fases escolares e docentes (Quadro 01).

Quadro o1: Ações do INEP na educação básica brasileira.

\begin{tabular}{|l|l|}
\hline $\begin{array}{l}\text { Índice de } \\
\text { Desenvolvimento da } \\
\text { Educação Básica (IDEB) }\end{array}$ & $\begin{array}{l}\text { Indicativo que traça metas de qualidade educacional nacional por meio de } \\
\text { escores de aprovação e de avaliações em larga escala. }\end{array}$ \\
\hline Censo Escolar & $\begin{array}{l}\text { Instrumento de coleta de dados escolares, estudantis e docentes da } \\
\text { educação básica. }\end{array}$ \\
\hline $\begin{array}{l}\text { Sistema de Avaliação da } \\
\text { Educação Básica (SAEB) }\end{array}$ & $\begin{array}{l}\text { Meio avaliador em larga escala que fornece os coeficientes para o IDEB. } \\
\text { Compóe-se por três testes: a ANEB/SAEB, ANRESC/Prova Brasil e ANA. } \\
\text { Provinha Brasil }\end{array}$ \\
\hline $\begin{array}{l}\text { Exame Nacional do do } \\
\text { Ensino Médio (ENEM) }\end{array}$ & $\begin{array}{l}\text { Avalia concluíntes no Ensino Médio; e serve também de Vestibular para o } \\
\text { Ensino Superior e para o pleito de vagas no PROUNI; bem como de } \\
\text { certificação no ENCEJA médio. }\end{array}$ \\
\hline $\begin{array}{l}\text { Exame Nacional para } \\
\text { Certificação } \\
\text { Competências de Jovens e } \\
\text { Adultos (ENCEJA) }\end{array}$ & $\begin{array}{l}\text { Promove a certificação, no ensino fundamental a pessoas que não tiveram } \\
\text { oportunidade de concluir seus estudos em idade própria. }\end{array}$ \\
\hline $\begin{array}{l}\text { Programme for } \\
\text { International Student } \\
\text { Assessment (PISA) }\end{array}$ & $\begin{array}{l}\text { Programa Internacional de Avaliação de Estudantes, desenvolvido pela } \\
\text { Organização para Cooperação e Desenvolvimento Econômico (OCDE), } \\
\text { projeta metas e indicadores educacionais globais. }\end{array}$ \\
\hline $\begin{array}{l}\text { Prova Nacional para } \\
\text { Ingresso na Carreira } \\
\text { Docente }\end{array}$ & $\begin{array}{l}\text { Iniciativa que visa subsidiar a realização de concursos públicos para o } \\
\text { ingresso e a contratação de docentes para a educação básica. }\end{array}$ \\
\hline
\end{tabular}

Fonte: Construído pela autora, baseado em INEP (2020).

O Índice de Desenvolvimento da Educação Básica (IDEB), criado em 2007, sob a responsabilidade do INEP, contempla um indicativo comparável nacionalmente que traça metas de qualidade educacional, que expressa, para o INEP (2020), "em valores os resultados mais importantes da educação: aprendizagem e fluxo”. Os escores de fluxo escolar são apurados a partir das taxas de aprovação no Censo Escolar; e as médias de desempenho/aprendizagem por meio de avaliações em larga escala em todos os níveis 
escolares. Efetivado por meio de um sistema eletrônico, que conta com a participação das escolas e colaboração dos distritos estaduais e municipais, o Censo Escolar é a principal coleta de informações da educação básica e tem seus dados coletados em âmbito nacional, a cada ano, em escolas públicas e privadas, nas diferentes etapas e modalidades de ensino, sobre estabelecimentos, turmas, aluno e profissionais escolares.

Quanto às testagens, o principal instrumento avaliador do INEP é o Sistema de Avaliação da Educação Básica (SAEB). Criado no final dos anos 1980 e nomeado de Sistema de Avaliação do Ensino Público (SAEP) de $1^{\circ}$ Grau, foi redimensionado na forma do SAEB e teve sua primeira aplicação no decênio de 1990. Esse, é um método de avaliação em larga escala e externo; em larga escala pela quantidade expressiva de alunos que envolve; e externo por ser concebido, planejado, elaborado, corrigido e ter resultados analisados fora da escola. Para o INEP (2020), esta "é uma metodologia adequada para avaliar redes ou sistemas de ensino, e não alunos individualmente", possibilitando com que resultados aferiram habilidades e competências estudantis passíveis de comparações por rede, escola e estudante, ao longo do tempo.

O SAEB, atualmente, é constituído pela Avaliação Nacional da Educação Básica (ANEB), realizada desde os primórdios do sistema. É uma avaliação amostral, inclui alunos de ensino fundamental e médio de redes privada e pública, que fornece o IDEB dos Estados e nacional. Abrange amostralmente alunos de redes públicas e privadas, de áreas urbanas e rurais, no $5^{\mathrm{o}}$ ano e $9^{\circ}$ ano do Ensino Fundamental e na $3^{\mathrm{a}}$ série do Ensino Médio. O modelo amostral inclui um grupo considerado estatisticamente representativo dos alunos do ano escolar avaliado, a fim de que os dados obtidos e as análises feitas possam ser considerados válidos para aquela população. Assim, tem um caráter global, mas não individualizado.

Por sua vez, a Avaliação Nacional do Rendimento Escolar (ANRESC) foi agregada ao SAEB em 2005, através de Portaria n. ${ }^{0}$ 931, de 21 de março, na forma de uma avaliação censitária do ensino público, realizada somente com alunos de ensino fundamental. Afere o IDEB detalhado por municípios e escolas, recebendo, por isso, o nome de Prova Brasil. É um tipo de avaliação censitária, o que quer dizer que abranger toda ou a maior parte dos alunos no período escolar testado, focalizando a obtenção de dados amplos sobre o desempenho da população, e a identificação de dados em conjunto

@rquivo Brasileiro de Educação, Belo Horizonte, v. 9, n. 18, 2021 
e de cada aluno avaliado. Cabe dizer que desde 2007 as provas da ANEB/SAEB e Prova Brasil são realizadas bianualmente juntas e medem habilidades de Língua Portuguesa (foco em leitura) e Língua Matemática (foco na resolução de problemas), tendo incluído desde 2013 também o teste em Ciências (no $9^{\circ}$ ano do Ensino Fundamental e na $3^{\mathrm{a}}$ série do Ensino Médio).

O SAEB conta ainda com a Avaliação Nacional da Alfabetização (ANA), aprovada em 2013. a partir da Portaria $n^{0}$ 482. O teste surgiu para servir de parâmetro para o Pacto Nacional pela Alfabetização na Idade Certa (PNAIC), Portaria n ${ }^{\circ} .867$, de 04 de julho de 2012, assim como para atender as Metas do Compromisso Todos pela Educação/PDE: alfabetizar todas as crianças até os 08 anos de idade e ao final do $3^{0}$ ano do ensino fundamental. Realizada anualmente e próximo ao final do ano letivo, de forma censitária, envolve estudantes no $3^{\circ}$ ano do Ensino Fundamental de escolas públicas por meio de um Teste de Desempenho em Língua Portuguesa e Matemática, e da avaliação das condições de oferta do Ciclo de Alfabetização.

Outra iniciativa promovida pelo INEP no âmbito escolar é a Provinha Brasil, instituída por Portaria $\mathrm{n}^{\mathrm{o}}$. 10, de 24 de abril de 2007, e aplicada desde o ano de $2008 \mathrm{em}$ periodicidade anual. Ela não é usada diretamente no IDEB, funcionando como um meio diagnóstico de alunos no $2^{\mathrm{o}}$ ano escolar e os quais já tenham cursado ao menos um ano de alfabetização. Sua efetivação se dá por meio da distribuição do Kit Provinha, elaborado pelo INEP e perpassado às secretarias educacionais municipais, estaduais e do Distrito Federal, ficando a cargo dos órgãos e redes locais a sua efetivação, que pode ser conduzida por professores do quadro interno e não obrigatoriamente por um agente externo. Sinteticamente, a prova afere habilidades de Leitura e Matemática, em duas etapas: no início do $2^{\mathrm{O}}$ ano escolar (preferencialmente, até o mês de abril) e no final letivo (sugerido que seja até o final de novembro). De tal modo, ainda que a Provinha não componha diretamente o IDEB, vê-se que o INEP (2020) deseja que seu uso oriente ações político-pedagógicas, que possam, junto com outras iniciativas, melhorar as práticas pedagógicas e com isso impulsionar o IDEB de estados e municípios, a médio e longo prazo. Ou seja, trata-se de uma estratégia de regulação do processo escolar que possibilitem atender ao SAEB e metas projetadas para a educação nacional.

Uma importante iniciativa do INEP é também o Exame Nacional do Ensino 
Médio (ENEM). Criado em 1998 e que até 2009 serviu especificamente para testar o desempenho do estudante no final da educação básica a partir de uma prova de 60 questões interdisciplinares e de múltipla escolha, além de uma prova dissertativa de Redação, quando então passou por reformulações e incluiu outras funções. A partir de 2009 o exame foi ampliado e se tornou, também, mecanismo seletivo de ingresso no ensino superior, tanto como fase única de seleção - que é o que acontece na maioria dos casos -, ou combinado com processos próprios de cada Universidade; passou a servir, ainda, para o pleito de vaga no Programa Universidade para Todos (PROUNI), criado pelo Governo Federal em 2004 para fornecer bolsas de estudo em instituições privadas de educação superior; além de funcionar, entre 2009 e 2017, como meio de certificação de jovens que não concluíram o ensino médio na idade adequada, mas, o certificado foi recentemente, em 2017, retornado a ser viabilizado pelo Exame Nacional para Certificação de Competências de Jovens e Adultos (ENCCEJA), assim como nos casos do ensino fundamental que já oferecem essa possibilidade desde 2002, de forma voluntária e gratuita, a pessoas, no Brasil ou no Exterior.

As mudanças no ENEM a partir de 2009 incluíram a sua reestruturação, mantendo a realização de uma prova Dissertativa de Redação, mas organizando-se daí em diante em quatro áreas do saber, contendo cada qual 45 questões de múltipla escolha. São elas: Ciências Humanas (disciplinas de História, Geografia, Filosofia e Sociologia); Ciências da Natureza (conhecimentos de Química, Física e Biologia); Linguagens e Códigos (comportando Língua Portuguesa, Literatura, Língua Estrangeira - Inglês ou Espanhol, Artes, Educação Física e as Tecnologias de Informação e Comunicação); Língua Matemática (que inclui apenas os conhecimentos matemáticos). Ainda que não contabilizado para o cálculo do IDEB, o exame conta com um sistema próprio, e a parte do SAEB, no qual os desempenhos são apresentados por área do conhecimento, individualmente, por escola e rede de ensino.

Para Lopes e López (2010), a concepção presente no ENEM apresenta indicadores que claramente apontam para a "construção de um discurso favorável à cultura da performatividade” (p. 90). Tem como foco o desenvolvimento de competências e habilidades, segundo uma perspectiva instrumental que limita o conhecimento ao saberfazer e se vincula a dimensões pragmáticas que reduzem a ideia de currículo, de 
conhecimento e de formação humana. Dessa forma, para as autoras,

O ENEM, como um sistema avaliativo que condensa os princípios da Reforma Educacional do Ensino Médio brasileiro, se constitui como um dispositivo que entrelaça e interpenetra o processo de ensino-aprendizagem em múltiplos níveis, já que, a partir dele, são engendrados tanto resultados globais (relativos às redes de ensino), quanto locais (referentes às unidades locais) e individuais (relativos ao aluno). Igualmente, o ENEM participa do fortalecimento e da circulação dos princípios da reforma, pois, em seu entrelaçamento e em seu processo de negociação com os múltiplos contextos com os quais se relaciona, produz efeitos mais ou menos convergentes de adesão a seus princípios (LOPES; LÓPEZ, 2010, p. 104).

Em fato, compreende-se que a noção de qualidade, traduzida nas avaliações tal como do ENEM e do SAEB, vinculadas a medir o que os alunos devem dominar, é incompatível com o processo pedagógico. A restrição da qualidade educativa a resultados e desempenhos desassocia as finalidades educacionais e reduz o sentido da educação. Por certo, melhorar a qualidade, como objetivo educacional, é desejável. Porém, deve-se colocar em pauta a concepção de qualidade que se defende, como fazer para atingi-la, e qual a função da escola e do professor nesse processo. A perspectiva de qualidade que se aspira reconhece a importância dos resultados educacionais, mas compreende ser preciso ir além, pois entende o sujeito em sua totalidade e a educação como lócus de formação humana (CÓSSIO, 2014).

Observa-se que as metas são importantes elementos, e projetam o caminho de evolução individual dentro dos índices escolares, segundo o INEP (2020), tendo-se, por isso, metas diferenciadas para cada rede e escola, apresentadas bienalmente para que cada Estado, município e escola se dediquem a melhorar seus índices para contribuir, em conjunto, para o Brasil alcançar um patamar de qualidade educacional. Essa meta do país foi fixada no Compromisso Todos pela Educação, o eixo central do Plano de Desenvolvimento da Educação (PDE), e a partir de então os sistemas municipais e estaduais se incumbiram de se ocupar de "28 diretrizes pautadas em resultados de avaliação de qualidade e de rendimento dos estudantes” (INEP, 2020).

Embora seja dito que "o Inep/MEC não tem o intuito de ranquear sistemas, ou impor parâmetros de qualidade que firam a autonomia das redes de ensino" (INEP, 2020), é explicito que o objetivo do IDEB é que seus resultados sejam "incorporados por professores, diretores, gestores e pela própria sociedade, fomentando um debate e um 
consequente trabalho pedagógico que subsidie a melhoria da qualidade educacional em todo o país" (INEP, 2020). Ou seja, é uma metodologia que suscita professores e escolas a práticas pedagógicas articuladas às metas educacionais, o que é bastante questionável pelo fato de condicionar o trabalho docente a parâmetros prescritivos e padronizados que esvaziam as potências autônomas e criativas.

Deve-se dizer que a referência para o IDEB é a média de 6,0 no ensino fundamental que equivale ao índice estipulado pela OCDE. Sendo que, para atingi-la uma das principais ações criadas pela OCDE é o Programme for International Student Assessment (PISA, em português Programa Internacional de Avaliação de Estudante. O Brasil participa do PISA desde sua primeira aplicação em 1998 (INEP, 2020). A prova é realizada de forma amostral e comparada e é aplicada a estudantes matriculados a partir do $8^{\circ}$ ano do Ensino Fundamental e com 15 anos - idade prevista para o término da escolaridade básica obrigatória na maioria dos países - a cada três anos focando em cada aplicação uma de três áreas, entre Leitura, Matemática e Ciências.

Conforme o site do INEP (2020), a penúltima rodada do PISA em 2015 teve 65 países participantes e inovou ao ser realizado, pela primeira vez, via computador e avaliar duas novas áreas: Competência Financeira e Resolução Colaborativa de Problemas. Já a última rodada da prova, realizada em 2018, se centrou na área de Leitura e contou com 79 países participantes, e envolveu também questionários com dados sobre professores, estudantes e suas famílias.

Pode-se dizer que os resultados do PISA servem como indicadores educacionais, tendo por base as perspectivas globais que orientam a OCDE e que se sustentam em princípios de cunho mercantis, empresariais, neoliberais e gerenciais, típicos de um Estado avaliador (FREITAS, 2011). Além disso, são características desse tipo de prática elementos como competitividade, individualidade e meritocracia, refletindo na organização das grades curriculares, nas práticas pedagógicas, nas formas didáticas, nos processos formativos de professores etc. relacionados uma determinada noção de qualidade educacional (CÓSSIO, 2014). 
Ao se observar as ações da OCDE, ressalta-se a ampliação de iniciativas para além do PISA ${ }^{1}$, o que inclui a criação da Pesquisa Internacional sobre Ensino e Aprendizagem (Teaching and Learning International Survey, TALIS) que tem em vista formar um modelo de professor. O TALIS resultou de um estudo prévio da organização (OCDE, 2006), produzido com apoio do BM, etc outros organismos mundiais. Seu objetivo é coletar dados comparáveis mundialmente sobre a profissão docente (baseando-se em critérios diversos, como liderança escolar, condições de trabalho e ensino, eficácia), para constituir um arcabouço sobre condições efetivas para qualificar o processo educacional. $\mathrm{Na}$ rodada atual de 2018, em sua terceira edição, segundo a OCDE (2018), mais de 45 países participaram do programa com vistas a aprofundar o debate internacional sobre como recrutar, preparar e manter as pessoas certas na docência.

Entende-se que o trabalho desenvolvido pela OCDE, através do TALIS imprime mudanças basilares na atividade docente, o que é fortalecido por ações e relações com outros organismos, como, por exemplo, o programa SABER/Teacher do BM.

O SABER/teacher é uma proposta resultante da agenda 2020 do BM (2011). Segundo o BM (2011) explicita, nesse então projeto é proposto fortalecer a obteção de resultados nos sistemas educativos próprios, a fim de subsidiar a construção de uma base de conhecimento de alta qualidade para a educação em nível global. Nesse sentido, propõe-se a criação de mecanismos de prestação de contas e de monitamento, com indicadores, respectivamente, de desempenho/performance, resultados e impacto performance, outcome, and impact indicators.

Assim sendo, o SABER/Teacher (BM, 2012) se traduz como uma iniciativa para alinhar as políticas docentes. O programa se desdobra, basicamente, em três etapas: primeiro coleta informações sobre as políticas para professores, via questionários, levantamento de dados quantitativos e documentações legais; depois analisa esses materiais e os classifica, de acordo com a forma como se comportam em oito núcleos

\footnotetext{
1 São outras iniciativas a plataforma de dados estatísticas do GPS educativo, e o Programa Internacional de Avaliação de Competências de Adultos (Programme for the International Assessment of Adult Competencies, PIAAC) que mede a proficiência de adultos em habilidades compreendidas como básicas (alfabetização, raciocínio e resolução de problemas em ambientes ricos em tecnologia). Seu início aconteceu em 2008, tendo como participantes 24 membros da OECD e noves países adicionais, de modo que em cada um deles pelo menos 5 mil pessoas, entre 16 e 65 anos, foram selecionadas aleatoriamente e, então, entrevistadas e avaliadas. Na última rodada, iniciada em 2014 e válida até 2018 , mais de 40 países participaram do programa.
} 
bases; finalmente, as análises são divulgadas na forma online, física e em workshops para subsidiar a melhoria da qualidade educacional.

Nos oito pontos que embasam o programa se percebe que pressupõem, ao cabo, motivar os professores para o desempenho/performance - "motivation teacher to perform" 2 (BM, 2012, p. 20). E, conforme dito no proprio site do BM (2018), atualmente, o foco tem recaído em quatro destes itens: atrair e reter os melhores para ensinar, buscando candidatos com históricos fortes, talentosos e orientados para a missão enquanto que docentes ineficazes sejam expelidos; promover treinamento mais diretivo e efetivo, com acompanhamento contínuo e técnicas concretas que ensinem a administrar a sala de aula; envolver os alunos, fomentando o processo de ensino, verificando a aprendizagem e explorando o know-how para solidificar métricas para atingir melhores resultados; e, por último, motivar os docentes para o desempenho, proporcionando práticas de ensino eficazes e oportunidades que os motivem e os recompensem.

Para Robertson (2013), projetos como o SABER/Teacher e TALIS representam uma intervenção significativa para controlar as práticas pedagógicas. Tais organismos tem uma capacidade de ação semelhante à dos aviões militares não tripulados (drones), pelo potencial de se embrenhar em fronteiras nacionais e espaços difíceis de luta militar sem estar presente fisicamente e são capazes de instituir um professor passível de ser controlado em suas decisões pedagógicas de um lado e de outro fortemente orientado pelas demandas econômico-financeiras e cada vez menos fora do alcance do Estado (ROBERTSON, 2013).

Com relação ao Brasil, destaca-se a iniciativa federal da Prova Nacional Docente, decretada por Portaria $\mathrm{n}^{\mathrm{o}}$. 03, de 02/03/2011, com a proposta de subsidiar estados, o Distrito Federal e municípios na realização de concursos públicos para o ingresso e a contratação de professores para a carreira. A Prova Docente teve uma experimentação em 2012 (INEP, 2016).

Vê-se que essa avaliação tem clara relação com outras iniciativas bem atuais no campo da profissão docente, como a Política Nacional de formação dos profissionais da

\footnotetext{
${ }^{2}$ São eles: 1) Definir expectativas claras para os professores; 2) Atrair os melhores para o ensino; 3) Preparar os professores com treinamento e experiência úteis; 4) Relacionar as habilidades dos professores às necessidades
}

@rquivo Brasileiro de Educação, Belo Horizonte, v. 9, n. 18, 2021 
educação básica, sancionada pelo decreto n.8752 de 08/05/2016. No Artigo 17 dessa proposta é manifestada sua sintonia com a Prova Docente, ao prever "harmonizar a conclusão da formação inicial com o início do exercício profissional” (BRASIL, 2016b). Outra ação com relações com a Prova Docente é o Projeto de Lei n. ${ }^{0}$ 6.114-A, de 2009 (BRASIL, 2016a), em situação de análise avançada dentro do governo federal, com vistas a avaliar os docentes atuantes nas escolas do país a partir da instituição de um Exame Nacional para o Magistério da Educação Básica (ENAMEB). De modo que, assim, a Prova Docente sirva como instrumento de admissão do professor à escola e o ENAMEB como certificação dos professores já atuantes.

Pode-se reconhecer o ENAMEB, Prova Docente e Política Nacional de Formação de Professores da Educação Básica como expressões da Base Nacional Curricular Comum (BNCC), política que tomou força em nível federal a partir de 2014 (BRASIL, 2018). A pretensão da BNCC é a de definir os conteúdos mínimos para as escolas do país, dentro de uma parte geral de base para ocupar dois terços do total curricular, ficando o restante a ser definido por cada rede de ensino.

Em 2016 o governo apresentou a primeira versão do documento, que depois perpassou por processos de rearticulação em versões subsequentes e ao final deixou mais fortemente evidentes pretextos econômicos e produtivos de viés gerencial e performativo. Destarte a isso, perto do encerramento de 2017 a versão final da BNCC voltada à Educação Infantil e ao Ensino Fundamental foi homologada pelo governo e passou a iniciar seu processo de execução nas redes de ensino do país. E o tocante ao Ensino Médio passou a ser elaborado em documento específico para se alinhar a proposta do Novo Ensino Médio, aprovado via Lei no 13.415 (BRASIL, 2017).

Segundo a página oficial da BNCC (BRASIL, 2018) seu propósito é, sinteticamente, dar suporte à (re) orientação das políticas de avaliação da educação básica, dos materiais didáticos e, também da política de formação inicial e continuada de docentes. Logo, é possível depreender o porquê de passarem a ser suscitadas iniciativas tais como àquelas representadas pelas políticas de formação de professores, Prova Docente e ENAMEB, a fim de atingir as premissas da BNCC.

estudantis; 5) Preparar professores líderes e diretores fortes; 6) Monitorar o ensino e a aprendizagem; 7) Apoiar os professores para melhorar a instrução; e, por fim, 8) Motivar os professores para o desempenho.

@rquivo Brasileiro de Educação, Belo Horizonte, v. 9, n. 18, 2021 
Uma ação já organizada em alinhamento à BNCC no âmbito do trabalho e formação docente aconteceu com a criação do Programa de Residência Pedagógica (PRP), em outubro de 2017, pouco após a homologação da BNCC para o Ensino Fundamental e a Educação Infantil, via edital específico para a adesão das instituições de ensino superior (CAPES 2018). O PRP apresentou a pretensão de reformulação do modelo de Estágios Supervisionados em cursos de Licenciatura, com o alargamento das vivências em sala de aula e na escola a futuros docentes, mas não como uma política universal, e na forma de programa prevendo o recrutamento de alguns licenciandos a partir de bolsas acadêmicas, o que o tornou alvo de muitas críticas. A perspectiva deflagrada de readequar os currículos e as propostas pedagógicas dos cursos de formação inicial de professores da educação básica à BNCC numa proposta mais prática, específica a alguns graduandos, tende para uma lógica tecnicista e sem maior densidade reflexiva e inclusiva no campo das lutas da área no sentido da formação ampliada entre teoria e prática.

Enfim, vê-se que é preciso questionar qual o motivo de avanço cada vez mais forte de políticas avaliativas de discentes a docentes. São medidas que impactam sensivelmente na função e no papel do magistério transformando-o em nível de seus valores, compromissos e motivações, ao incitá-lo a perspectivas do mundo de negócios e a critérios de competição e individualismo. Trata-se de práticas recorrentemente vistas de forma naturalizada e apolítica, as quais escondem o fato de que a profissão docente uma vez orientada a melhorar os resultados e desempenhos é retirada de compromissos sociais mais amplos quanto a quê e para quê serve.

\section{Finalizando: a necessidade de reafirmar o papel da escola e do professor.}

Esse estudo teve por objetivo analisar as políticas educacionais no Brasil e alguns de seus impactos sobre o trabalho docente na escola.

A escola pública é o grande espaço de formação estudantil brasileira, algo correspondente a cerca de 80\% do total da faixa estudantil do país (INEP, 2014; MEC, 2015). E os docentes, são sujeitos chave na intermediação da relação de ensinoaprendizagem na escola. É por meio dos processos pedagógicos, didáticos e avaliativos 
viabilizados pelos professores que se consolida o projeto de formação escolar daquilo que se entende e se deseja que os estudantes aprendam.

Contudo, veem-se questões latentes envolvendo a escola pública brasileira no contexto das políticas educacionais vigentes, com desdobramentos no modelo de trabalho docente.

Observou-se que a interpelação do modelo de gestão gerencialista, típico daquele promovido no ambiente empresarial, enfoca metas e indicadores que no Brasil são promovidos com o IDEB, juntamente de avaliações externas e em larga escala realizadas com alunos e até mesmo de docentes, construindo um universo de responsabilização sobre o sucesso, ou fracasso, educacional como resultado da incompetência do professor, da escola, e do próprio aluno, que acaba por suprimir o desamparo por parte do Estado da função de provedor e, em fato, de grande responsável, de regular a coisa pública, tal que a educação.

Mostrou-se importante debater sobre os efeitos no trabalho docente, e, em consequência, na perspectiva de educação que é evocada, pelo foco em desempenhos que é incitado a partir das cultura de avaliação externa e em larga escala, com a padronização curricular para melhorar os resultados, com a fragmentação da formação e do trabalho docente quando se alinha a essas lógicas e torna o professor um executor e técnico que se orienta pela melhoria de resultados, muitas vezes, de forma concorrencial e individualista, no cenário de políticas sociais e de um tipo de Estado avaliador que está voltado a atender à economia global.

À medida que os imaginários docentes são minados por exigências e expectativas que lhe são impostos externamente, e, em grande medida, sem devido amparo e formação, ou mesmo condições de trabalho, seu cotidiano é rondado por metas, ranking, e um sentido de qualidade educacional em que são recorrentes questionamentos tais que: Quê direção considerar para desenvolver minhas práticas? Como definir o programa de ensino e onde buscar as bases, instrumentos e conhecimentos para fazê-lo? Oriento-me pelas indicações programáticas do SAEB, da Provinha Brasil, do ENEM e mesmo do PISA, que inclinam a satisfação pessoal docente a um produto de obtenção de boas notas?

No esteio de tal concepção que permeia a cultura de desempenhos o

@rquivo Brasileiro de Educação, Belo Horizonte, v. 9, n. 18, 2021 
reconhecimento social docente (principalmente por parte dos pais dos alunos e da comunidade em geral) passa, muitas vezes, a ser resumido pelo potencial de obter boas notas, as quais são incrementadoras do IDEB, em nível nacional, e em nível internacional do ranking brasileiro no PISA. Nisso, os professores escolares são estimulados a atingirem esses índices, o que os envolve em preocupações com os conteúdos a serem trabalhados para a preparação dos testes, enquanto aqueles que não são foco nas provas se tornam de menor importância. As escolas são incitadas para que compartilhem desse mesmo espírito coletivo, tornando-se escolas performáticas e que melhorem seus desempenhos, como sinal de escolas de qualidade. A valoração das avaliações e dos bons resultados, o estímulo a competição entre escolas, entre professores, entre alunos, em busca de melhorar seus resultados, torna-se elemento chave do sucesso e mérito de si próprio como pessoa e em seu trabalho.

Enfim, as problematizações colocadas em questão é que os docentes são envolvidos em uma atmosfera profissional passiva, voltada a atender exigências externas, no lugar de ações democráticas de cunho ativo e motivadas internamente por um compromisso local com a comunidade atendida. É um modelo de atividade docente que se orienta em individualidade e competividade, ao invés de se relacionar com aspectos como coletividade, solidariedade e cooperação que são características de um projeto escolar de qualidade socialmente referenciada, construído localmente e a serviço da comunidade escolar. Promove-se com isso um perfil docente técnico e despolarizado, dentro de uma concepção comensurável, objetivável e descomplexificada da educação, vinculada a uma forma de docência orientada pela performatividade, contraposta a um modelo docente socialmente construído.

Entende-se que considerar apenas a variável das notas para nivelar a Educação Básica brasileira como o IDEB faz é problemático. Prova Brasil, SAEB e IDEB e programas diretamente voltados aos docentes, tais que a Prova Docente e desdobramentos da BNCC, devem ser instrumentos de monitoramento, diagnóstico e não instrumentos de pressão e responsabilização. As avaliações educacionais precisam ser articuladas com a avaliação institucional e a sala de aula, ou seja, "três níveis de avaliação (sistema, escola e sala de aula) devem estar trabalhando articuladamente", como diz Freitas (2007, p. 979). Logo, “os governos não podem "posar" de grandes 
avaliadores, sem olhar para seus pés de barro, para suas políticas, como se não tivessem nada a ver com a realidade educacional do país de ontem e de hoje" (FREITAS, 2007, p. 975).

Conforme bem diz a síntese de Afonso (2007),

[...] tendo em conta a complexidade da realidade social e educacional, não posso, no entanto, defender mecanismos de avaliação que, muitas vezes, parecem pretender medir apenas desempenhos cognitivos ou aspectos instrumentais, deixando na penumbra uma série de outras dimensões educativas, entre as quais, a promoção de uma concepção ampliada de cidadania e uma visão crítica e sustentada do mundo e da vida. Defendo, por isso, que a escola (pública ou privada) com qualidade só pode ser uma escola simultaneamente democrática e com elevadas possibilidades de propiciar aprendizagens efectivas em termos científicos, técnicos e humanísticos. A qualidade deverá ser, não apenas científica, mas também pedagógica e democrática - e a avaliação destas qualidades não se pode resumir à aplicação de testes estandardizados ou a outras formas idênticas de avaliação externa. Por isso, ao contrário do que, por vezes, nos fazem crer, a adopção de certos dispositivos de avaliação externa (sobretudo os que são exclusivamente baseados em indicadores quantificáveis e mensuráveis) não contribuirá para a tão propagandeada melhoria da qualidade do ensino, representando antes um retrocesso político e educacional injustificável quando comparado com os progressos científicos e epistemológicos que têm vindo a conduzir a avaliação para perspectivas anti-positivistas, mais complexas, pluralistas, democráticas e objectivas. Aliás, a emergência do chamado Estado-avaliador tem significado um importante retrocesso porque, entre outras razões, promoveu a recuperação, actualização e predomínio de muitos dos pressupostos e instrumentos positivistas e quantitativistas em avaliação, favorecendo, assim, a desvalorização social e política da complexidade dos processos sociais e educativos (p. 19-20).

Os tipos de testagens avaliativas que responsabilizam apenas a parte da comunidade escolar, em consonância do descompromisso de governantes para com a qualidade da educação, e em prevalência no âmbito público, fazem parte de um movimento mais amplo das ideias gerenciais, enquanto motores potentes para a hegemonização do programa global, tanto ao disseminar os valores e princípios de mercado, como para propiciar espaços para o mercado atuar e aumentar seus lucros por meio da ruína e fragmentação do caráter público e estatal da educação.

Considera-se ser necessário desvelar o avanço de tais modelos de políticas sobre escola e docentes, mostrando o curso de um projeto social que exaure a educação e esvazia a função dos bens-públicos. Tem reflexos na impotência de um projeto social mais justo e igualitário, desumanizando a vida da imensa maioria populacional que se escolariza nesse espaço e do trabalho realizado pelos professores que atuam neles, na

@rquivo Brasileiro de Educação, Belo Horizonte, v. 9, n. 18, 2021 
medida em que aliena as práticas docentes e as faz servirem à lógica do mercado e não aos interesses populares.

Com isso, o professor passa a se sentir, em uma totalizante marginalização e desvalorização a respeito do papel social de seu trabalho, sobretudo, em vista de um Estado que se abstém tanto de promovê-lo como pessoa e profissional reconhecido pelas tarefas que realiza no campo da educação, enquanto bem público, e como fonte de elevação sociohumanitária.

São vastos os dilemas que se produzem sobre o professor, colocando diretamente em pauta o potencial e o significado de suas ações pedagógicas. Pois, afinal, como pode o professor se dedicar a um trabalho ao qual se é continuamente responsabilizado, sem, todavia, verdadeiramente valorizado, especialmente por quem deveria apoiá-lo e propiciar as condições para realizar suas atividades com efetiva qualidade e compromisso social?

\section{REFERÊNCIAS:}

ADRIÃO, Theresa; PERONI, Vera Maria Vidal. A educação pública e sua relação com o setor privado: Implicações para a democracia educacional. Revista Retratos da Escola, Brasília, v. 3, n. 4, p. 107-116, jan./jun. 2009.

AFONSO, Almerindo. Estado, políticas educacionais e obsessão avaliativa. Contrapontos, v. 7, n. 1, Itajaí, jan/abr, p. 11-22, 2007.

ANDERSON, Perry. Balanço do Neoliberalismo. In: Pós-neoliberalismo: as políticas sociais e o Estado democrático. Rio de Janeiro: Paz e Terra, 1995.

ANTUNES, Ricardo. Mesa redonda: Mercado informal, empregabilidade e cooperativismo: as transformações das relações de trabalho no mundo contemporâneo. Cadernos de Psicologia Social do Trabalho, v. 2, $\mathrm{n}^{0}$ 1, p. 55-72, 1999.

. Trabalho e precarização numa ordem neoliberal. In: A cidadania negada.

2001, p. 35-48. Disponível em: http://www.estudosdotrabalho.org/TextosReestruturacao.html. Acesso em 10/04/2015.

BALL Stephen. Diretrizes Políticas Globais e Relações Políticas Locais em Educação. Currículo sem Fronteiras, v.1, n.2, pp.99-116, Jul/Dez, 2001.

- Profissionalismo, Gerencialismo e Performatividade. Cadernos de Pesquisa, v. 35, $\mathrm{n}^{0}$. 126, set./dez, p. 539-564, 2005. 
. Sociologia das políticas educacionais e pesquisa crítico-social: Uma revisão pessoal das políticas educacionais e da pesquisa em política educacional. Currículo sem Fronteiras, v.6, $\mathrm{n}^{\circ}$. 2, Jul/Dez, p. 10-32, 2006.

BM, Banco Mundial. Estratégia 2020 para a Educação: Resumo Executivo. Washington DC, 2011

. SABER/Teacher. What matters most in teacher policies? A framework for building a more effective teaching profession. Washington DC: WB, jul 2012.

. Site oficial. Disponível em: <http://saber.worldbank.org/index.cfm>. Acesso em: 11 ago. 2018.

BRASIL. Base Nacional Curricular Comum. Site institucional. Disponível em: http://basenacionalcomum.mec.gov.br. Acesso em 20/01/2018.

- Projeto de Lei n. ${ }^{0}$ 6.114-A/2009: Exame Nacional de Avaliação do Magistério da Educação Básica (ENAMEB). Disponível em: ttp://www.camara.gov.br/proposicoesWeb/fichadetramitacao?idProposicao $=452755$. Acesso em 20/05/2016a.

- Presidência da República Casa Civil. Subchefia para Assuntos Jurídicos. Decreto $n^{0}$ 8.752, de 09/05/2016. Dispõe sobre a Política Nacional de Formação dos Profissionais da Educação Básica. Brasília, 2016.

. Lei no 13.415, de 16 de fevereiro de 2017. Disponível em: http://www.planalto.gov.br/ccivil_03/_Ato2015-2018/2017/Lei/L13415.htm. Acesso em: 01/12/2018.

CAPES, Coordenação de Aperfeiçoamento de Pessoal de Nível Superior. Programa de Residência Pedagógica. Publicado em o1 de março de 2018. Disponível em: http://www.capes.gov.br/educacao-basica/programa-residencia-pedagogica. Acesso em $01 / 12 / 2018$.

CLARKE, Jonh; NEWMAN, Janet. Gerencialismo. Educação e Realidade, v. 37, nº . 2, maio/ago, p. 353-381, 2012.

CÓSSIO, Maria de Fátima. Avaliação em larga escala e as novas formas de regulação da educação nacional. III CONAVE, Bauru, 2014.

FREITAS, Luiz Carlos. Eliminação adiada: O caso das classes populares no interior da escola e a ocultação da (má) qualidade do ensino. In: Educação e Sociedade. Campinas, v. 28, n. 100, out, p. 965-987, 2007.

- Responsabilização, meritocracia e privatização: conseguiremos escapar ao neotecnicismo? In: Seminário de Educação Brasileira, Centro de Estudos

@rquivo Brasileiro de Educação, Belo Horizonte, v. 9, n. 18, 2021 
Educação e Sociedade, Campinas, fev., 2011.

HARVEY, David. Condição pós-moderna. São Paulo: Loyola, 2013.

HOOD, Christopher. The "New Public Management" in the 1980s: Variations on a theme'. Pergamon, Accounting, Organizations and Society, v. 20, n. 3, p. 93-109, 1995 .

INEP, Instituto Nacional de Estudos e Pesquisas Educacionais Anísio Teixeira. Censo Escolar da Educação Básica 2013: resumo técnico. Brasília, 2014.

. Site oficial. Disponível em: http://portal.inep.gov.br. Acesso em: 20/03/2020.

. Prova Nacional Docente. Disponível em: http://portal.inep.gov.br/provadocente. Acesso em 20/05/2016.

KUENZER Acácia Z. A formação de professores para o Ensino Médio: velhos problemas, novos desafios. Educação e Sociedade, v.32, nº . 116. Campinas, 2011.

MAINARDES, Jefferson. A abordagem do ciclo de políticas e suas contribuições para a análise da trajetória de políticas educacionais. Atos de pesquisa em educação, v. 1, $\mathrm{n}^{\mathrm{o}}$ 2, maio/ago, p. 94-105, 2006.

MAROY, Christian; VOISIN, Annelise. As transformações recentes das políticas de accountability na educação: desafios e incidências das ferramentas de ação pública. Educação \& Sociedade, v. 34, n. 124, 2013, pp. 881-901.

MEC, Ministério da Educação. Dados Censo Escolar - 2015. Disponível em: http://portal.mec.gov.br/index.php?option $=$ com_docman\&view $=$ download\&alias $=1704$ 4-dados-censo-2015-11-02-materia\&Itemid=30192. Acesso em 10/03/2016.

MÈSZÁROS, István. Para além do Capital. São Paulo: Boitempo, 2013.

OCDE, Organização de Cooperação e Desenvolvimento Econômico. Professores são importantes: atraindo, desenvolvendo e retendo professores eficazes. São Paulo: Moderna, 2006.

TALIS 2018: Survey. Paris: OECD, 2018. Disponível em: <http://www.oecd.org/education/school/TALIS_2018_brochure_ENG.pdf >. Acesso em: 10 dez. 2019.

OLIVEIRA, Dalila Andrade. Reestruturação do trabalho docente: precarização e flexibilização. Educação e Sociedade, v. 25, nº. 89, Set-dez, p. 1127-1144, 2004.

PERONI, Vera Maria Vidal. As redefinições na relação público/privado e as implicações para a democratização da educação. Congresso Sul-brasileiro da ANPAE, p. 1-17, 2010.

@rquivo Brasileiro de Educação, Belo Horizonte, v. 9, n. 18, 2021 
- Redefinições no papel do Estado: Parcerias público-privadas e a democratização da educação. Arquivos Analíticos de Políticas Educativas, v. 21, $\mathrm{n}^{0} .47$, maio, p.1-16, 2013.

ROBERTSON, Susan. As implicações em justiça social da privatização nos modelos de governança da educação: Um relato relacional. Educação e Sociedade, Campinas, v. 34, n. 124, p. 679-703, jul.-set. 2013.

SHIROMA, Eneida; CAMPOS, Roselane; GARCIA, Rosalba M. Decifrar textos para compreender a política: subsídios teórico-metodológicos para análise de documentos. Perspectiva. Florianópolis, v. 23, n. 02, p. 427-446, 2005.

\section{SOBRE A AUTORA:}

Susana Scherer: Doutora em Educação pela Universidade Federal de Pelotas (UFPel), Mestre e Licenciada em Educação Física UFPel. Realizou Estágio Doutoral na Universidade do Minho - Portugal com supervisão do Prof. Licínio Lima. É integrante do Núcleo de Estudos e Pesquisas e Políticas Educacionais (NEPPE-UFPel). E-mail: susana_scherer@hotmail.com

\section{Tramitação:}

Recebido em:19/04/2021

Aprovado em:24/o6/2021 